Revista Digital Universitaria

Vol. 23, Núm. 1, enero-febrero 2022

\title{
Videojuego para la enseñanza de celdas solares: diseño e integración al aula
}

\author{
Asiel Neftalí Corpus Mendoza, Ana Belén Cortés Díaz, Paola \\ Marcela Moreno Romero, Mateus Torres Herrera y \\ Carlos Alberto Rodríguez Castañeda
}

\begin{abstract}
Resumen
Nuestro Sol es un proveedor inagotable de energía para la vida en la Tierra. Su luz puede ser aprovechada y convertida en electricidad por medio de tecnologías fotovoltaicas para beneficio de la vida humana. Sin embargo, el desarrollo de dichas tecnologías requiere de una variedad de conocimientos que incluyen áreas de física, química, ingeniería eléctrica y electrónica, ciencia de materiales, entre otras. Esto representa un reto en el proceso de enseñanza-aprendizaje para profesores y estudiantes de carreras afines, así como un obstáculo en la motivación de ambos. Por lo tanto, en este artículo se propone utilizar un videojuego sencillo, ilustrativo, interactivo y divertido que facilite el aprendizaje de un tema abstracto, multidisciplinario y complejo como la fabricación y caracterización de celdas solares de perovskita híbrida. En este videojuego, los estudiantes son libres de fabricar celdas solares. Cada etapa de construcción requiere decisiones con impacto directo en la eficiencia del dispositivo construido, en otras palabras, la proporción de energía solar convertida en electricidad. Además, cada decisión involucra los conceptos básicos de química y física de materiales, así como teoría de semiconductores aprendidos en el aula. Así, los estudiantes pueden aprender sobre la fabricación de celdas solares en una forma interactiva, eficiente y amigable.
\end{abstract}

Palabras clave: videojuegos, gamificación, tecnologías de la educación, educación interactiva, celdas solares.

\section{VIDEO GAME FOR TEACHING SOLAR CELLS: DESIGN AND INTEGRATION INTO THE CLASSROOM}

\begin{abstract}
Our Sun is an inexhaustible provider of energy for life on Earth. Its light can be harnessed and converted into electricity through photovoltaic technologies for the benefit of human life. However, the development of such technologies requires a variety of knowledge that includes areas of physics, chemistry, electrical and electronic engineering, materials science, and others. This represents a challenge in the teachinglearning process for teachers and students of related careers, as well as an obstacle in the motivation of both. Therefore, this article proposes the use of a simple, illustrative, interactive, and fun videogame that facilitates the learning of an abstract, multidisciplinary, and complex topic such as the fabrication and characterization of hybrid perovskite solar cells. In this videogame, students are free to fabricate solar cells. Each stage of construction requires decisions with a direct impact on the efficiency of the fabricated device, in other words, the proportion of solar energy converted into electricity. Also, each decision involves the understanding of basics concepts of chemistry and physics of materials, as well as semiconductors theory learned in the classroom. Thus, students can learn about solar cell fabrication in an interactive, efficient, and friendly way.
\end{abstract}

Keywords: videogames, gamification, technologies for education, interactive education, solar cells. 
"Videojuego para la enseñanza de celdas solares: diseño e integración al aula" Asiel Neftalí Corpus Mendoza, Ana Belén Cortés Díaz, Paola Marcela Moreno Romero, Mateus Torres Herrera y Carlos Alberto Rodríguez Castañeda Vol. 23, Núm. 1, enero-febrero 2022 Revista Digital Universitaria

Asiel Neftalí Corpus Mendoza, PhD

ancm@ier.unam.mx orcid.org/0000-0003-1529-1923

Recibió el título de Ingeniero Electrónico por parte del Instituto Tecnológico de Mexicali en 2009 y el grado de doctor en Ingeniería Eléctrica y Electrónica por parte de la Universidad de Sheffield, UK en 2017. Su especialidad es la caracterización eléctrica de distintas tecnologías fotovoltaicas y el desarrollo de circuitos eléctricos equivalentes para el análisis de celdas solares. Actualmente se desempeña como investigador y profesor en el Instituto de Energías Renovables - UNAM, donde continúa su investigación en fabricación y caracterización de celdas solares. También le interesa el uso de ciencia de datos para explorar distintos problemas relacionados a energías renovables y al medio ambiente, así como el uso de juegos con fines educativos.

\section{Ana Belén Cortés Díaz}

ana.cortesd@alumno.buap.mx

Estudiante de la licenciatura de Arte Digital en la Benemérita Universidad Autónoma de Puebla. Soy una artista generalista dedicándome a la ilustración, animación, modelado 3D y programación de videojuegos, aunque mis intereses actuales son la programación de shaders y el storyboard.

\section{Dra. Paola Marcela Moreno Romero}

orcid.org/0000-0001-8522-6970

Doctora en Ingeniería en Energía de la Universidad Nacional Autónoma de México - UnAm. Maestra en Ingeniería en Energía de la unAm. Licenciada en Química de la Universidad Pedagógica Nacional de Colombia. Desde 2017 hasta la actualidad, ha estado trabajando en el desarrollo y evaluación de celdas solares emergentes basadas en películas delgadas de perovskita. Sus intereses de investigación incluyen procesos que permitan el diseño, instalación y gestión de laboratorios químicos y docentes.

\section{Dr. D. Mateus Torres Herrera}

orcid.org/0000-0002-4689-0964

Ingeniero en Energía por la Universidad Politécnica de Chiapas (2014). Maestro y Doctor en Ingeniería (Energía) por el Instituto de Energías Renovables de la Universidad Nacional Autónoma de México $(2016,2021)$. Su trabajo se centra en el desarrollo de películas delgadas de semiconductores inorgánicos para su aplicación como capas transportadoras de carga y modificadores interraciales en celdas solares basadas en perovskitas híbridas.

\section{Dr. Carlos Alberto Rodríguez Castañeda}

orcid.org/0000-0001-9900-1019

Recibió el grado de Ingeniero Industrial y de Sistemas en 2008 por la Universidad del Valle de México, así mismo, recibió el grado de Ingeniero en Energía en 2013 por la Universidad Politécnica del Estado de Guerrero. Realizó el programa de residencia en el Laboratorio de Confiabilidad Fotovoltaica (ASU-PRL) en 2015 por la Universidad Estatal de Arizona. Posteriormente, recibió el grado de Maestro en Ingeniería y el grado de Doctor en Ingeniería, ambos por la Universidad Nacional Autónoma de México entre 2014 y 2021. Desde 2017 hasta la actualidad, ha trabajado en el desarrollo y evaluación de celdas solares emergentes basadas en óxidos semiconductores y películas delgadas de perovskita. Ha publicado 8 artículos en revistas indexadas con factor de impacto. Sus intereses de investigación incluyen estudios de control de calidad y confiabilidad de la tecnología fotovoltaica. 
"Videojuego para la enseñanza de celdas solares: diseño e integración al aula" Asiel Neftalí Corpus Mendoza, Ana Belén Cortés Díaz, Paola Marcela Moreno Romero, Mateus Torres Herrera y Carlos Alberto Rodríguez Castañeda Vol. 23, Núm. 1, enero-febrero 2022 Revista Digital Universitaria

\section{Introducción}

$\mathrm{E}$ uso masivo de dispositivos inteligentes e internet en el siglo xxl ha influenciado la forma de vida y métodos de aprendizaje de millones de estudiantes. Este contacto con la tecnología ha atraído a los jóvenes hacia carreras universitarias relacionadas con tecnologías informáticas sobre las ciencias duras o ingenierías tradicionales. El desinterés o miedo hacia la ciencia se debe parcialmente tanto a su contenido abstracto, como también a la escasez de métodos de enseñanza-aprendizaje con carácter interactivo y amigable, como lo puede ser la creación de contenido, la participación en redes sociales, o incluso un videojuego. Por ejemplo, el temario de celdas solares fotovoltaicas en las carreras de física o ingeniería electrónica, tradicionalmente involucra la enseñanza de conceptos abstractos y complejos como teorías de electromagnetismo, densidad de estados electrónicos de semiconductores, interfaces metal-semiconductor y uniones semiconductor-semiconductor. Estos conceptos resultan difíciles de asimilar por parte del estudiante debido a la falta acompañamiento práctico, pues los métodos de fabricación y caracterización de las celdas solares convencionales, como el silicio y los semiconductores $\| I-v$, son muy costosos y requieren de un profundo entrenamiento para su uso adecuado, lo cual dificulta su implementación en las universidades en general. Regularmente, esto limita la educación práctica de celdas solares a la construcción de circuitos electrónicos simples donde la energía solar se convierte en energía eléctrica.

Sin embargo, desde hace más de 20 años los investigadores comenzaron a desarrollar celdas solares con tecnológicas de "química suave" (O'Regan et al., 1991), las cuales emplean soluciones químicas a temperaturas bajas sin necesidad de alto vacío ni cuarto limpio para la producción de celdas solares. Estas celdas reciben el nombre de celdas solares emergentes o de tercera generación, de la cuales las más eficientes son las de perovskita híbrida (Figura 1). En estas celdas se utiliza una perovskita o material de estructura cristalina para absorber la luz y producir pares de cargas eléctricas negativas y positivas llamadas, electrones y huecos, respectivamente. Dichas cargas son colectadas por las capas transportadoras de electrones y huecos para posteriormente circular a través de un circuito externo y así encender un dispositivo. Actualmente, la eficiencia récord o conversión de energía solar en electricidad de las celdas solares de perovskita superan el 25\% (Green et al., 2021), poniéndolas casi a la par de las celdas de silicio cristalino. Desde el punto de vista de la docencia, lo más interesante de estas nuevas tecnologías es la relativa facilidad de su producción sin requerir equipos sofisticados. Como ejemplo, los estudiantes de posgrado de Ingeniería (Energía) de la unAm han logrado fabricar celdas fotovoltaicas de perovskita híbrida con eficiencias de más de 19\% en áreas de 0.1 cm2. Además, han impartido cursos de fabricación de celdas en los que los participantes sin previa experiencia logran obtener celdas con eficiencia mayor a 14\%. Esta experiencia resulta sumamente emocionante y satisfactoria para los aprendices por lograr hacer celdas solares con sus propias manos en menos de una semana en un laboratorio relativamente modesto. Sin embargo, las 
"Videojuego para la enseñanza de celdas solares: diseño e integración al aula" Asiel Neftalí Corpus Mendoza, Ana Belén Cortés Díaz, Paola Marcela Moreno Romero, Mateus Torres Herrera y Carlos Alberto Rodríguez Castañeda Vol. 23, Núm. 1, enero-febrero 2022 Revista Digital Universitaria

Figura 1. Estructura de perovskita, donde usualmente $\mathrm{A}=(\mathrm{CH} 3 \mathrm{NH} 3) 2+, \mathrm{B}=\mathrm{Pb} 4+, \mathrm{X}=12-$ La estructura de una celda solar consiste en diferentes capas de materiales.

Fuente. Elaboración propia. características interdisciplinarias del proceso dificultan la totalidad de su comprensión, por ejemplo, a los químicos se les dificulta la física de semiconductores, y a los físicos e ingenieros se les complica entender los mecanismos de reacción en las soluciones precursoras antes de la formación de las películas activas. Es urgente buscar nuevos métodos de enseñanza para las materias interdisciplinarias.
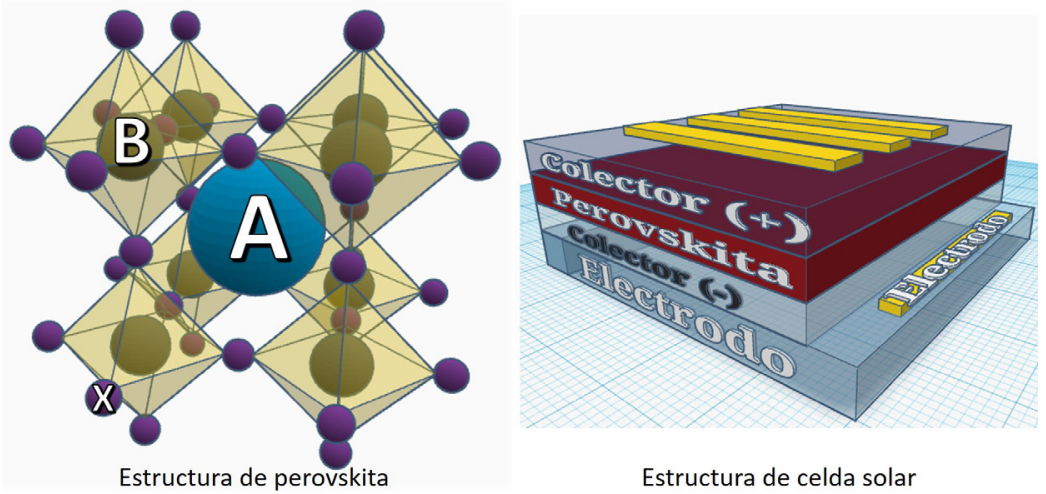

En este artículo describimos el desarrollo de un videojuego sencillo, pero a la vez interesante y atractivo, para la enseñanza-aprendizaje de conceptos básicos de química de materiales y física de dispositivos electrónicos aplicados en la clase de celdas solares. Este producto describe de manera divertida e interactiva el proceso de preparación de celdas solares de perovskita híbrida y la correlación entre este proceso y el desempeño de las celdas. De esta forma, los estudiantes pueden entender con mayor facilidad los conceptos básicos de química de materiales y física de dispositivos electrónicos al mismo tiempo que obtienen satisfacción tras completar una serie de retos.

\section{¿Por qué un videojuego?}

Un instrumento educativo interactivo permite al estudiante tomar sus propias decisiones y experimentar sus respectivas consecuencias, logrando así obtener conocimientos por medio del descubrimiento. En este sentido, un videojuego es un instrumento visual interactivo que puede crear ese ambiente de exploración y descubrimiento para el o la estudiante (jugador o jugadora). Dentro de los diversos tipos de videojuegos, hay un género llamado juegos serios (LópezRaventós, 2016) o gamificación (Martí-Parreño et al., 2015), en los que se usan los elementos del diseño de juego para su aplicación en sectores de empresa, salud y educación (Martí-Parreño et al., 2015). El objetivo de este tipo de videojuegos es crear entornos de aprendizaje que permitan experimentar con problemas reales con el fin de ensayar y explorar múltiples soluciones a problemas planteados en situaciones reales, y descubrir la información y los conocimientos que ayudarían a intervenir sin temor a equivocarse (López-Raventós, 2016). Este tipo de simulaciones facilita el tomar decisiones que no tienen consecuencias en la vida real, pero que enseñan las opciones óptimas en diferentes situaciones (López-Raventós, 2016). Este tipo de juegos serían adecuados para ser un nuevo método de enseñanza-aprendizaje del tema de celdas solares. 
"Videojuego para la enseñanza de celdas solares: diseño e integración al aula" Asiel Neftalí Corpus Mendoza, Ana Belén Cortés Díaz, Paola Marcela Moreno Romero, Mateus Torres Herrera y Carlos Alberto Rodríguez Castañeda Vol. 23, Núm. 1, enero-febrero 2022 Revista Digital Universitaria

En efecto, la preparación y caracterización de una celda solar es un proceso de toma de decisiones que involucra diversos métodos de limpieza de sustratos, depósitos de diferentes capas de materiales con diferentes técnicas en condiciones cambiantes, y hasta procesos únicos de caracterización/ evaluación de la celda. La toma de decisiones en cada paso de la preparación de la celda solar impacta en los pasos siguientes y por lo tanto, en la eficiencia de conversión de la misma. Es detrás de estas decisiones donde se ponen a prueba los conocimientos científicos multidisciplinarios tales como física o química de superficies, crecimiento de cristales, etc. Por lo tanto, los estudiantes aprenden los conocimientos básicos a través de un experimento de toma de decisiones para lograr la meta de mejorar la eficiencia de conversión. A través de este proceso uno ve la importancia de los conocimientos básicos en solucionar un problema real, lo cual podrá hacer las carreras de ciencias e ingenierías más atractivas y enriquecedoras para los jóvenes en general.

Nuestro objetivo es desarrollar un videojuego que enseñe la interrelación entre el proceso de preparación y el desempeño fotovoltaico de una celda solar de perovskita con la finalidad de mejorar la experiencia de aprendizaje del alumno o alumna y así facilitar el proceso de enseñanza-aprendizaje de materias con contenido multidisciplinario. Para ello primero diseñamos un diagrama de flujo de los procesos de preparación y caracterización de una celda solar de perovskita híbrida para su integración al videojuego. Posteriormente identificamos los elementos químicos, moléculas, procesos de fabricación, dispositivos y técnicas de caracterización involucrados en laboratorio, así como su representación gráfica e interacción dentro de un videojuego. Finalmente desarrollamos un prototipo del videojuego incorporando los elementos identificados, y lo probamos en un grupo controlado para evaluar su funcionamiento e impacto en el aprendizaje de los alumnos.

\section{Diseño de un videojuego}

Un videojuego se compone de mecánicas, dinámicas y estéticas. Las mecánicas son las diversas acciones, comportamientos y mecanismos que el jugador puede controlar dentro del juego. Describen el objetivo del juego y cómo el jugador puede o no obtenerlo (Figura 2). En este caso, las mecánicas incluyen los comandos básicos para desplazar al personaje, el acceso a menús de ítems, la operación de equipos de laboratorio como centrifugadoras, evaporador térmico y cámara de guantes, así como los procesos simulados para construir cada una de las capas de la celda solar.

Las dinámicas son el resultado del comportamiento de dichas mecánicas al interactuar con el jugador y entre ellas. Las dinámicas se desarrollan a partir de los distintos elementos que influyen sobre el proceso principal. En este caso, las dinámicas pueden incluir una variedad de ítems o artículos con que experimentar, y sustancias por combinar, así como las interacciones que se pueden dar entre ellos (Figura 3), las decisiones tomadas por el jugador para 
Figura 2. Diagrama de flujo propuesto para las mecánicas del videojuego.

Fuente. Elaboración propia.

Figura 3. Interacciones entre ítems del videojuego tal como ocurren en el laboratorio.

Fuente. Elaboración propia. construir su celda solar, las consecuencias de sus decisiones y el resultado final en términos de eficiencia de celda.
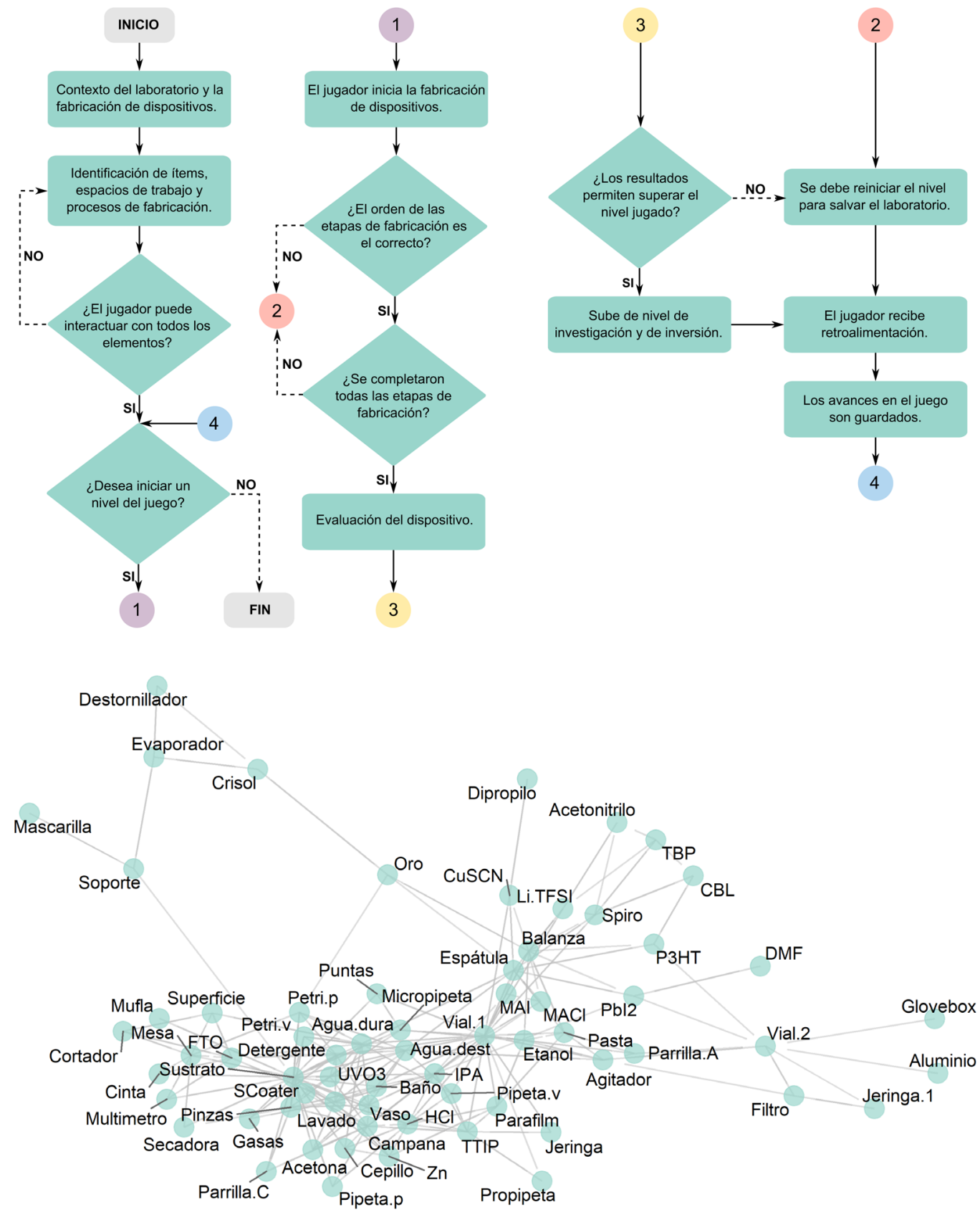

Por último, las estéticas son la respuesta emotiva que se espera evocar en el jugador. Son las que atraen al jugador al juego, por ejemplo, los personajes (Figura 4), o la música. Desde la perspectiva del desarrollador, las mecánicas provocan las dinámicas que en su lugar dirigen a ciertas estéticas. En cambio, desde la perspectiva del jugador, las estéticas construyen el tono, que se observa en las dinámicas y eventualmente en el control de las mecánicas. 
Figura 4. Estética del personaje y sus etapas de diseño. Fuente. Elaboración propia.

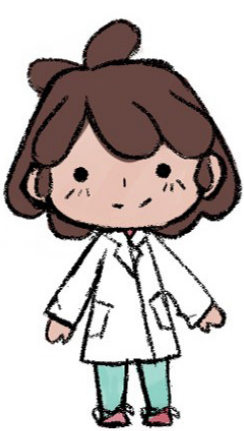

Arte concepto

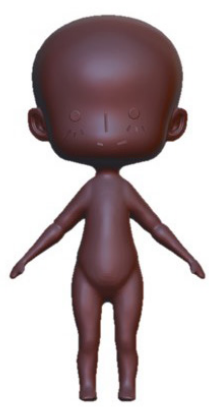

Referencias musculares

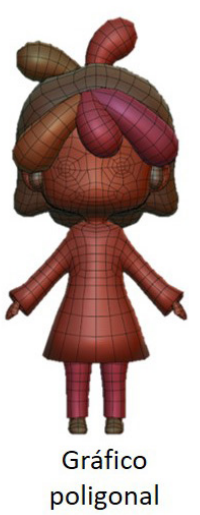

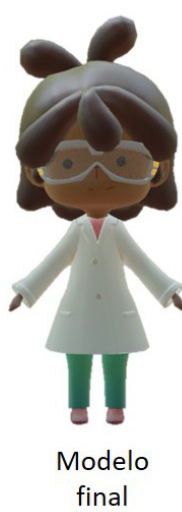

Es importante que el producto final tenga un equilibrio entre los elementos atractivos de los videojuegos y los elementos educativos a presentar. Por tal razón hemos incluido datos reales de celdas solares de perovskita híbrida fabricadas en nuestro laboratorio como parte de los indicadores a evaluar en el videojuego. Esto incluye más de cien recetas usadas en preparación de celdas solares, las cuales resultan en eficiencias variables (Arias-Ramos et al., 2020; Corpus-Mendoza et al., 2018; García-Cerrillo et al., 2017; Moreno-Romero et al., 2019; Rodríguez-Castañeda et al., 2020). De esta forma, el jugador es libre de fabricar celdas con la estructura de su preferencia y de experimentar múltiples parámetros de fabricación correlacionados a resultados experimentales reales para ofrecer un aprendizaje significativo.

\section{Videojuego propuesto}

SAVE PEROVSKITE!, es un juego de simulación y construcción con fines educativos, donde el personaje principal investiga y desarrolla celdas de perovskita híbrida para rescatar la inversión de su laboratorio y evitar su clausura. El juego se divide en 9 fases de producción, donde el jugador es guiado en la fabricación. Así, el jugador se familiariza con los materiales, herramientas y áreas de trabajo. Después de cada fase, el jugador es recompensado con un incremento en su nivel de investigación. Finalmente, las celdas completadas son evaluadas para retroalimentar al jugador sobre su proceso y plantear su siguiente experimento.

El escenario de juego es un ambiente 3D basado en un laboratorio real con áreas de trabajo, máquinas, herramientas, gavetas y más (Figura 5). Durante el proceso de fabricación ocurren tres tipos de eventos, los cuales son, simulación, configuración y automático. En los eventos de simulación, el jugador entra a un minijuego que asemeja la forma en que se realiza el proceso real. En los eventos de configuración, el jugador ajusta los parámetros de operación de los equipos y añade los reactivos a usar. Estos eventos requieren un tiempo de espera para concluir, lo cual obliga al jugador a ser organizado en su proceso. Por último, los eventos automáticos proveen animaciones dependiendo de las acciones del jugador. 
Figura 5. Etapas de diseño del escenario Fuente. Elaboración propia.

Video. Save Perovskite Demo. (Dr. Asiel Corpus, 2021).

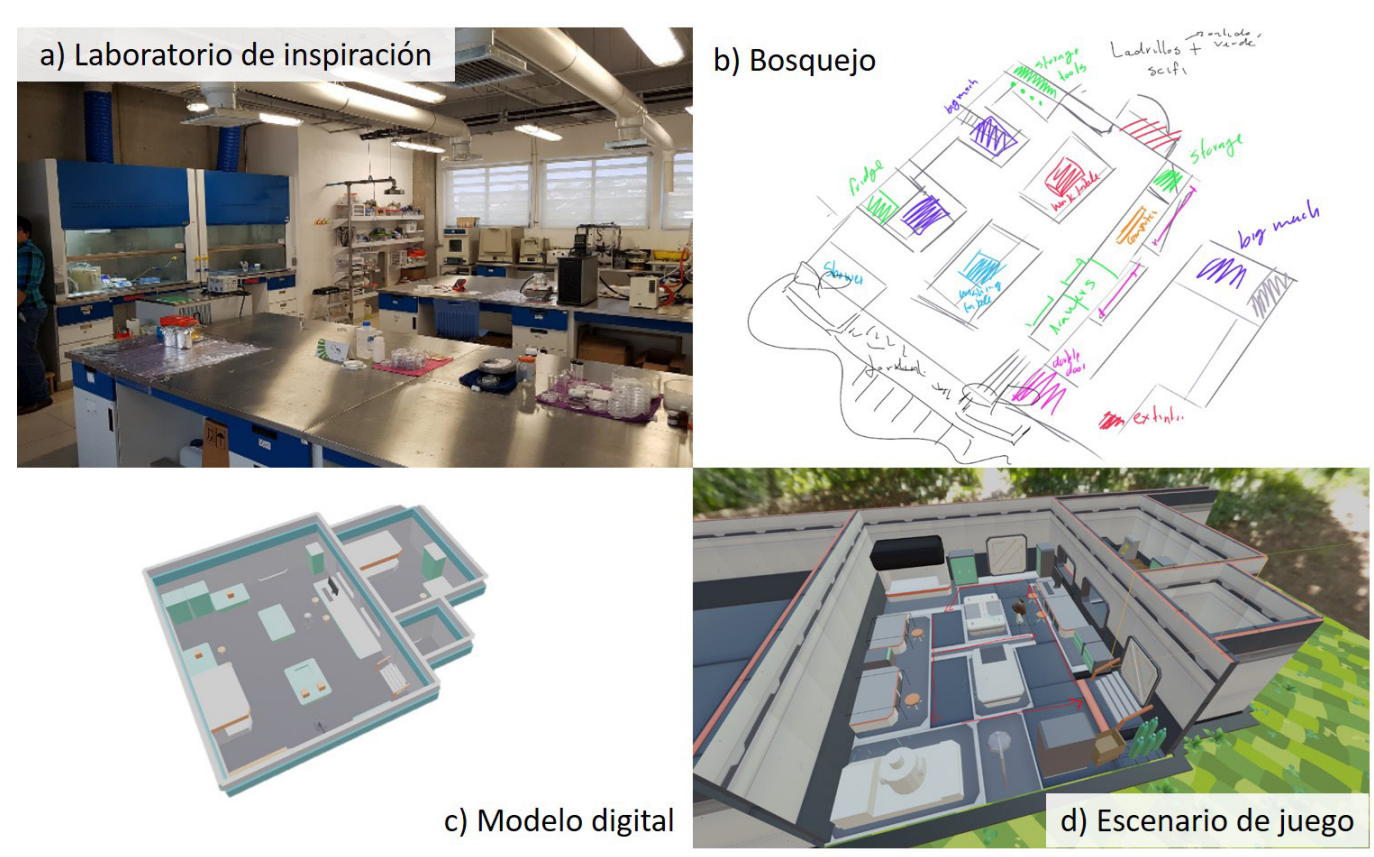

Los diferentes experimentos realizados por el jugador son registrados en una bitácora de fabricación, la cual puede ser consultada para planear futuros experimentos. Además, el jugador recibe consejos y pistas a lo largo de su experimentación con el objetivo de ayudarlo en su progreso en el juego y al mismo tiempo, educarlo sobre el proceso de fabricación de celdas solares y otros conceptos fotovoltaicos en la vida real. Finalmente, el jugador gana al terminar exitosamente sus experimentos y elevar el nivel de investigación hasta un nivel seguro para evitar la clausura del laboratorio. Actualmente es posible encontrar un video demostrativo del videojuego en desarrollo en:

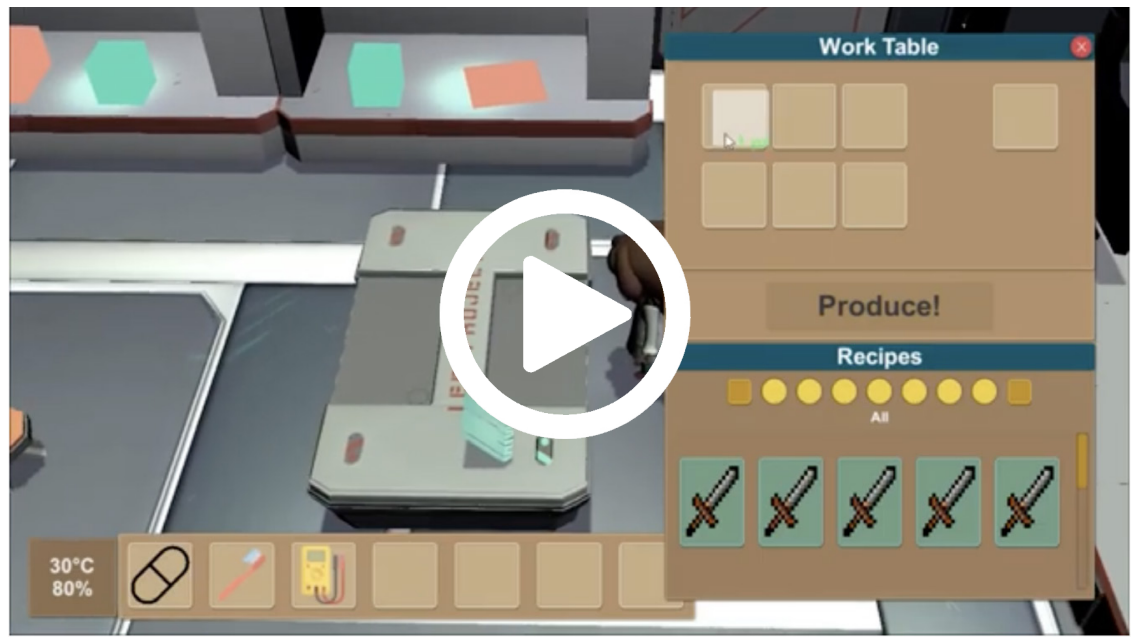




\section{Conclusiones}

En este artículo se propone el uso de videojuegos educativos como una herramienta complementaria para la enseñanza y aprendizaje de materias multidisciplinarias. Con esto se busca promover el entusiasmo de los estudiantes hacia las asignaturas y carreras que comúnmente son consideradas complejas, abstractas o aburridas, como son, la ciencia y la ingeniería. Además, se busca que el proceso de experimentación libre implementado en el videojuego contribuya a la curiosidad del estudiante por aprender, así como a su capacidad para diseñar y conducir experimentos y procedimientos de laboratorio que pueden llegar a ser muy costosos en la práctica, como lo es la fabricación de celdas solares.

\section{Sitios de interés}

- Página de grupo

- Perovskitas en el IER

- Instagram: @solar_noobs

\section{Agradecimientos}

Proyecto unAM-PAPIME PE102820 y a la Dra. Hailin Hu por su participación.

\section{Referencias}

* Arias-Ramos, C. F., Kumar, Y., Abrego-Martínez, P. G. y Hu, H. (2020). Efficient and stable hybrid perovskite prepared at $60 \%$ relative humidity with a hydrophobic additive in anti-solvent. Solar Energy Materials \& Solar Cells, 215, 110625-1 110625-9. https://doi.org/10.1016/j.solmat.2020.110625

* Corpus-Mendoza, A. N., Moreno-Romero, P. M. y Hu, H. (2018). Impact of magnetic fields on the morphology of hybrid perovskite films for solar cells. AIP Advances, 8, 055221-1 - 055221-6. https://doi.org/10.1063/1.5026797

* Dr.AsielCorpus. (2021, 26 septiembre). Save Perovskite Demo [video]. YouTube. https://www.youtube.com/watch?v=56uwOeB2wjU

* García-Cerrillo, J., Corpus-Mendoza, A. N., Moreno-Romero, P. M., HernándezGranados, A. y Hu, H. (2017). Improvement of the morphological and electrical characteristics of $\mathrm{Al} 3+$, Fe3+ and $\mathrm{Bi3}+$-doped $\mathrm{TiO} 2$ compact thin films and their incorporation into hybrid solar cells. Materials Science in Semiconductor Processing, 72, 106 - 114. DOl:10.1016/j.mssp.2017.08.027

* Green, M. A., Dunlop, E. D., Hohl-Ebinger, J., Yoshita, M., Kopidakis, N. y Ho-Baillie, A. W. Y. (2021). Solar cell efficiency tables (Version 57). Prog. Photovoltaics Res. Appl., 29, 3-15. https://doi.org/10.1002/pip.3371 
* López-Raventós, C. (2016). "El videojuego como herramienta educativa. Posibilidades y problemáticas acerca de los serious games", Apertura, revista de innovación educativa, 8(1), 136-151. http://www.udgvirtual.udg.mx/apertura/ index.php/apertura/article/view/825/539.

* Martí-Parreño, J., Queiro-Ameijeiras, C., Méndez-Ibáñez, E. y Giménez-Fita, E. (2015, 21 de julio). El uso de la gamificación en la educación superior: el caso de trade ruler [ponencia]. XII Jornadas Internacionales de Innovación Universitaria Educar para transformar: Aprendizaje experiencial, Madrid, España. https:// abacus.universidadeuropea.es/handle/11268/4314

* Moreno-Romero, P. M., Corpus-Mendoza, A. N., Millán-Franco, M. A., RodríguezCastañeda, C. A., Torres-Herrera, D. M., Liu, F. y Hu, H. (2019). Roughness and Structural Modification of Pbl2 Thin Films by Isopropanol Treatment to Improve Methylammonium Lead Halide Formation and Solar Cell Efficiency. Journal of Materials Science: Materials in Electronics, 30, 17491-17503. https://doi. org/10.1007/s10854-019-02100-7

* O'Regan y Grätzel, B. (1991). A low-cost, high-efficiency solar cell based on dye-sensitized colloidal TiO2 films. Nature, 353, 737-470. https://doi. org/10.1038/353737a0

* Rodríguez-Castañeda, C. A., Moreno-Romero, P. M., Corpus-Mendoza, A. N., Suárez, G., Miranda-Hernandez, M., Sotelo-Lerma, M. y Hu, H. (2020). Thermal evaporation -oxidation deposited aluminum oxide as an interfacial modifier to improve the performance and stability of zinc oxide based planar perovskite solar cells, ACS Appl. Energy Mater. 3, 9618-9627. DOI:10.1021/acsaem.0c01106

\section{Cómo CITAR ESTE ARTículo}

* Corpus Mendoza, Asiel Neftalí, Cortés Díaz, Ana Belén, Moreno Romero, Paola Marcela, Torres Herrera, D. Mateus, Rodríguez Castañeda, Carlos Alberto. (2022, enero-febrero). Videojuego para la enseñanza de celdas solares: diseño e integración al aula. Revista Digital Universitaria (RDU), 23(1). http://doi.org/10.22201/ cuaieed.16076079e.2022.23.1.4 